\title{
Metodología para el estudio de la gestualidad en la plástica románica de los reinos hispanos
}

\author{
Alicia Miguélez CAVERo \\ Universidade Nova (Lisboa)
}

\section{RESUMEN}

En este trabajo se señalan los presupuestos metodológicos empleados para analizar el papel jugado por la gestualidad como medio de expresión y comunicación en el arte románico de los reinos hispanos.

Palabras clave: Gestos; iconografía; arte románico.

\section{Methodology for the study of gestures in the Romanesque iconography of the Spanish Kingdoms}

\begin{abstract}
This paper presents the methodology we have used to analyse the role played by gestures as a vehicle of expression and communication in the Romanesque art of the Spanish Kingdoms.
\end{abstract}

Keywords: Gestures; iconography; Romanesque Art.

Este trabajo, de carácter teórico, pretende mostrar los planteamientos y procedimientos metodológicos que han sido utilizados para llevar a cabo un estudio sobre la gestualidad en la iconografía románica de los reinos hispanos.

Dicha investigación tuvo como punto de partida la Memoria de Licenciatura que realizamos bajo el título: "Actitudes gestuales en la iconografía del románico peninsular hispano: el sueño, el dolor espiritual y otras expresiones similares". En ella procedimos a analizar un gesto, el de llevarse la mano a la mejilla, que en la iconografía románica fue utilizado para plasmar, gráficamente, un estado del ser humano, el sueño; un sentimiento, el del dolor interno; así como otras manifestaciones, por ejemplo la meditación ${ }^{1}$. Este tema se amplió posteriormente con un análisis más profundo de la gestualidad en la iconografía románica peninsular, que constituyó nuestra Tesis Doctoral bajo el título "Gesto y gestualidad en el arte románico de los reinos hispa-

1 MIGUÉLEZ CAVERO, Alicia, Actitudes gestuales en la iconografia del románico peninsular hispano. El sueño, el dolor espiritual y otras expresiones similares, León, Universidad, Secretariado de Publicaciones, 2007. 
nos. Lectura y valoración iconográfica"2. La intención del presente escrito es exponer los fundamentos teóricos que sirvieron de base para llevarla a cabo.

\section{Material de trabajo}

El material de trabajo que hemos utilizado para la realización de este estudio se basa en tres pilares fundamentales: en primer lugar, en obras de arte románicas de los reinos hispanos, así como del resto de los territorios europeos donde la plástica románica tuvo un especial desarrollo. Además, se ha llevado a cabo también un profundo rastreo de piezas y obras artísticas del mundo antiguo, de aquellas civilizaciones y culturas donde surgieron muchos de los gestos utilizados, posteriormente, en el período medieval. Asimismo, hemos indagado en épocas posteriores, especialmente la Baja Edad Media, momento en el que se produjo un gran desarrollo gestual en la iconografía gótica y en el que podemos hallar una continuidad en la utilización de muchas conductas.

El segundo de los campos que han constituido el material de trabajo básico para la realización de esta Tesis Doctoral son textos de carácter literario, filosófico y estético, tanto del período en el que se centra la investigación como del mundo antiguo. Éstos son una fuente indispensable a la hora de analizar el significado y origen de muchas de las conductas gestuales que hallamos en la plástica románica.

Por último, el tercero de los pilares en los que se sustenta esta investigación es el aparato bibliográfico, formado por estudios procedentes de diversos campos científicos, entre los que se encuentran la antropología, la lingüística, la historia y, por supuesto, la historia del arte.

\section{Planteamiento metodológico}

Desde el punto de vista metodológico, el desarrollo de la investigación ha sido dividido en dos bloques. En el primero de ellos hemos intentado establecer una serie de planteamientos teóricos, para después pasar a realizar un corpus gestual del arte románico en los reinos hispanos.

En el primer bloque, dedicado, como decimos, a analizar cuestiones de carácter teórico, hemos estudiado aquellas ciencias, disciplinas y áreas de conocimiento que se han ocupado del estudio de los gestos, cuyas aportaciones son fundamentales para el desarrollo de nuestro propio trabajo de investigación.

2 La Tesis Doctoral fue dirigida por la Prof. Dra. Dña. Etelvina Fernández González y defendida el 12 de noviembre de 2009 en la Facultad de Filosofía y Letras de la Universidad de León. Gracias a la obtención del premio del Certamen de Tesis Doctorales convocado anualmente por Círculo Románico. Centro de Estudios del Románico, dicho trabajo de investigación ha sido recientemente publicado: MIGUÉLEZ CAVERO, Alicia, Gesto y gestualidad en el arte románico de los reinos hispanos. Lectura y valoración iconográfica, Madrid, Multimedia S.L., 2010. 
Existe, por un lado, un grupo de disciplinas relacionadas con la lingüística, entre las que cabe destacar la semiótica y la kinésica ${ }^{3}$. Por otro lado, podemos hablar de otro conjunto de disciplinas, que también se ocupan del análisis del lenguaje gestual, y que está formado por los estudios de psicología, antropología, sociología y proxémica ${ }^{4}$. En estrecha relación con las disciplinas que acabamos de mencionar estaría un tercer grupo, dedicado al estudio de los gestos desde el punto de vista de la biología y la etología, ciencia ésta última fundada por $\mathrm{Ch}$. Darwin y que se encarga del "estudio científico del carácter y modos de comportamiento del hombre".

Por lo que respecta al campo de las humanidades, se ha generado también, de manera progresiva, un gran interés por estudiar el papel e importancia de la gestualidad en distintas épocas de la historia, así como en diferentes ámbitos como historia del arte, filosofía y literatura. Desde el siglo XIX se han ido sucediendo distintas publicaciones que se centraban en el estudio de los gestos.

En cuanto a los gestos y la gestualidad en el mundo antiguo, son destacables los estudios llevados a cabo por la historiografía alemana desde finales del siglo XIX, por ejemplo los trabajos de C. Sittl ${ }^{6}$. Éstos han tenido su continuidad durante el siglo XX, produciéndose en los últimos años un gran desarrollo a nivel mundial ${ }^{7}$.

3 La semiótica, o teoría de los signos, es una disciplina surgida a finales del siglo XIX a partir de las investigaciones del filósofo Charles Sanders Peirce y del lingüista Ferdinand de Saussure y tiene por objeto el estudio de los hechos significativos. Véase: MADSEN, Peter, "Sign and Significance in Aesthetic Análisis-Beyond Semiotics”, en Kodikas/Code. Ars Semeiotica, vol. 14, no 3/4, 1991, p. 318 y GUTIÉRREZ ORDÓÑEZ, Salvador, Introducción a la semántica funcional, Madrid, Síntesis, 1989, p. 17. Por su parte, la ciencia de la kinésica, nacida en la década de los años cincuenta a partir de los trabajos del antropólogo y psiquiatra R. L. Birdwhistell, es la disciplina que estudia el significado expresivo de los gestos y de los movimientos corporales que acompañan los actos lingüísticos. Cf.: BIRDWHISTELL, Ray L., Kinesics and Context: Essays on Body Motion Communication, Pennsylvania, University Press, 1970; POYATOS, Fernando, La comunicación no verbal II. Paralenguaje, kinésica e interacción, Madrid, Istmo, 1994 e Id., "La lengua hablada como realidad verbal- no verbal: nuevas perspectivas", en BRIZ, Antonio, GÓMEZ, José, MARTÍNEZ, Ma José Martínez y Grupo Val. Ed. Co (eds.), Pragmática y gramática del español hablado. Actas del II Simposio sobre análisis del discurso oral, Valencia, Universidad, 1996, p. 216.

4 Esta última, la proxémica, es una disciplina surgida en los años 60, cuyas bases y objetivos fueron definidos por el antropólogo E. T. Hall. Se ocupa del estudio de la percepción y uso que el hombre hace del espacio físico. Analiza los posibles tipos de distancia que se pueden establecer entre las personas, cómo se pueden diferenciar esas distancias o qué relaciones, actividades y emociones pueden asociarse con cada tipo de distancia. Aunque presenta puntos de estudio en común con la kinésica, el objetivo principal de la proxémica no es la observación y análisis de los movimientos y expresiones corporales, sino que se decanta por otros elementos como la arquitectura, el uso del espacio y los modos en que el hombre percibe la distancia. Cf.: HALL, Edward T., "Proxemics", en Current Anthropology, vol. 9, n 2/3, 1968, pp. 83-108. 684.

Cf. Voz "etología”, en Diccionario de la Real Academia, vigésima segunda edición, Madrid, 2001, p.

6 SITTL, Carl, Die Gebärden der Griechen und Römer, Leipzig, B. G. Teubner, 1890.

Destacan obras clave como: ALDRETE, Gregory S., Gestures and Acclamations in Ancient Rome, Baltimore, Johns Hopkins University Press, 1999; BAKEWELL, Geoffrey - SICKINGER, James (eds.). Gestures. Essays in ancient history, literature and philosophy presented to Alan L. Boegehold, Oxford, Oxbow Books, 2003; BODIU, Lydie, FRÈRE, Dominique, MEHL, Véronique, L'expression des corps. Gestes, attitudes, regards dans l'iconographie antique, Rennes, Presses Universitaires, 2006; BREMMER, Jan, ROODENBURG, Herman (eds.), A Cultural History of Gesture: from Antiquity to the present, with an introduction 
Lo mismo ocurre con la investigación sobre los gestos en la Edad Moderna: han ido surgiendo sucesivamente estudios sobre la gestualidad, siendo especialmente significativos los trabajos de A. Chastel y M. Barasch ${ }^{8}$. En relación con los estudios sobre el Renacimiento, es imprescindible citar la obra de A. Warburg, una figura esencial del campo de las humanidades en el siglo XX. Centró sus investigaciones en la transmisión de la cultura e iconografía antiguas a épocas posteriores, así como en el arte del Renacimiento italiano, intentando demostrar que en ese momento de la historia se había producido un renacer del paganismo de carácter dionisiaco. A partir de 1924 y hasta su muerte, en 1929, se dedicó exclusivamente a la realización de un gran proyecto denominado Bilderatlas Mnemosyne, en el que recopiló cerca de 2000 reproducciones y fotografías de obras de arte de todas las épocas de la historia y en el que los gestos jugaron un papel esencial. A. Warburg analizó la manera en que éstos se habían desarrollado en el arte de la Antigüedad y cómo los artistas de épocas posteriores los habían utilizado y les habían ido añadiendo contenidos nuevos. Según este historiador del arte, los gestos presentes en las artes visuales servían para dominar, de alguna manera, la violencia de las pasiones y dar a éstas una forma más digna y contenida 9

En lo concerniente, específicamente, al mundo medieval, época en la que se centra nuestro estudio, los gestos han sido estudiados desde el punto de vista de la historia de las mentalidades, la historia del arte, la literatura y la filosofía, entre otras disciplinas ${ }^{10}$. Durante toda la centuria pasada fueron surgiendo obras y estudios, aunque ha sido en las últimas décadas cuando las publicaciones y la celebración de congresos específicos sobre este tema se han ido sucediendo a un ritmo vertiginoso $^{11}$.

by sir Keith Thomas, Cambridge, Polity Press, 1993; MONTSERRAT, Dominic, Changing Bodies, Changing Meanings. Studies on the Human Body in Antiquity, London, Routledge, 1998.

8 BARASCH, Moshe, Gestures of Despair in Medieval and Early Reinassance, New York, University Press, 1976; Id., Giotto and the language of gesture, Cambridge (U.S.A.), University Press, 1990; CHASTEL, André, El gesto en el arte, Madrid, Siruela, 2004; Id., "Gestures in Painting: Problems in Semiology", en Reinassance and Reformation, vol. 10, $\mathrm{n}^{\circ}$ 1, 1986, pp 1-22.

9 Las cerca de 2000 reproducciones fueron colocadas por A. Warburg y sus colaboradores en diversos paneles y expuestas en la Biblioteca Warburg de Hamburgo así como en la Biblioteca Hertziana de Roma. Tras la muerte del historiador del arte, y como consecuencia del auge del nazismo y el comienzo de la II Guerra Mundial, su colaborador Fritz Saxl consiguió trasladarla a Londres, donde se convertiría en el Instituto Warburg. Actualmente, en la colección fotográfica de este Instituto se conserva todavía una cantidad considerable de las fotografías y reproducciones del proyecto Mnemosyne. La sección de la biblioteca dedicada a los gestos es, asimismo, muy amplia. Sobre todo ello véase: GOMBRICH, Ernst, Aby Warburg: an Intelectual Biography, London, The Warburg Institute, 1970; LÜDEKING, Karlheinz, "Pictures and Gestures", en British Journal of Aesthetics, vol. 30.3, 1990, p. 229; y WARBURG, Aby, Der bilderatlas Mnemosyne, hrsg. von Martin Warnke unter Mitarbeit von Claudia Brink, Berlin, Akademie Verlag, 2003.

10 Según M. Castiñeiras, el renovado interés hacia los gestos en el estudio de la imagen medieval se podría situar en la línea de los modelos lingüísticos de la antropología y de la cinésica americana. Véase sobre esto: CASTIÑEIRAS GONZÁLEZ, Manuel, Introducción al método iconográfico, Barcelona, Ariel, 1998, p. 26, n. 11.

${ }^{11}$ Quizá una de los primeros estudios dedicados al estudio de la gestualidad en época medieval desde el punto de vista plástico y literario sea la disertación llevada a cabo por DELLING, Hildegard, Studien über die Gebärdensprache in Dichtkunst und Bildkunst des frühen und hohen Mittelalters, Leipzig, 1925. Desde 
Sin embargo, en comparación con notable cantidad de estudios en otros territorios europeos, la aportación realizada por la historiografía de la Península Ibérica es mucho menor. Hasta el momento de la realización de este trabajo de investigación no se había realizado un estudio profundo y exhaustivo sobre estos aspectos en el arte románico peninsular hispano. De ahí el aliciente de llevar a cabo un estudio sobre este tema.

Para ello, se ha tomado como base y referencia constante, a lo largo de toda la investigación, el estudio de los gestos y la gestualidad en las disciplinas señaladas anteriormente, así como en el ámbito de la civilización medieval en otros países. Por ello, en la primera parte de nuestra investigación, dedicada a los planteamientos teóricos, nos hemos ocupado de señalar la importancia de los gestos dentro del proceso de comunicación del ser humano. Asimismo, hemos intentado hacer una clasificación de los mismos según su forma, significado y origen.

Tras estos planteamientos, con los que hemos pretendido sentar las bases teóricas para nuestra investigación, nos hemos ocupado de la realización y estudio de un corpus gestual, es decir, de la configuración de un conjunto de gestos, maneras y posturas presentes en la iconografía románica de los reinos hispanos. Dicho corpus se ha llevado a cabo mediante un estudio riguroso de cada uno de los gestos que hemos incluido en el mismo. Los tres criterios de clasificación de los gestos señalados en el bloque de los planteamientos teóricos, es decir, la forma, el significado y el origen, son los mismos criterios por los que hemos optado a la hora de realizar una clasificación de los gestos en la iconografía del arte románico en territorio peninsular hispano.

\section{Procedimiento metodológico del corpus gestual}

El procedimiento metodológico que hemos seguido para analizar cada una de las conductas gestuales del corpus ha sido el siguiente: en un primer momento nos

entonces se han sucedido los estudios sobre la gestualidad en la Edad Media, destacando principalmente los trabajos relacionados con las historiografías francesa, alemana, inglesa e italiana. Podemos señalar, por ejemplo, los trabajos de los investigadores galos F. Garnier y J.-C. Schmitt. Cfr. GARNIER, François, Le langage de l'image au Moyen Âge. Signification et symbolique, Tours, Le Léopard d'Or, 1995 e Id., Le language de l'image au Moyen Age II. Grammaire des gestes, París, Le Léopard d'Or, 2003; SCHMITT, Jean-Claude, La raison des gestes dans l'Occident médiévale, Paris, Gallimard, 1990. Por lo que respecta a la historiografía germana, destacan los estudios del profesor G. Althoff y R. Schmidt-Wiegand, así como la reciente obra de M. Mrass: MRASS, Marcus, Gesten und Gebärden. Begriffsbestimmung und-verwendung in Hinblick auf kunsthistorische Untersuchungen, Regensburg, Schnell \& Steiner, 2005. En relación con la historiografía italiana, aunque reuniendo a especialistas procedentes de otros territorios, debemos mencionar la Settimana anual de Spoleto del año 2004, que estuvo dedicada al análisis de conceptos como la comunicación, en la que la gestualidad juega un papel fundamental: Atti delle LII Settimane di Studio della Fondazione Centro Italiano di Studi sull'alto Medioevo: Communicare e significare nell'alto Medioevo, 15-20 aprile 2004, 2 vols., Spoleto, Fondazione Centro Italiano di Studi sull' Alto Medioevo, 2005. Por último, fuera del ámbito europeo, es obligado citar los estudios realizados en Estados Unidos, donde, en torno a C. Davidson se han publicado diversos trabajos sobre la relación entre los gestos y los dramas litúrgicos en el mundo medieval. Su trabajo más relevante, en este sentido, es: DAVIDSON, Clifford, Gesture in medieval drama and art, Kalamazoo, Medieval Institute Publications, Western Michigan University, 2001. 
planteamos la existencia de un gesto en el ámbito geográfico y temporal señalado y analizamos su representación formal e iconográfica de manera general en el arte románico europeo, y en el de la Península Ibérica en concreto. A continuación, indagamos sobre su posible significado o significados y, a partir de este aspecto, buscamos su origen (fig. 1).

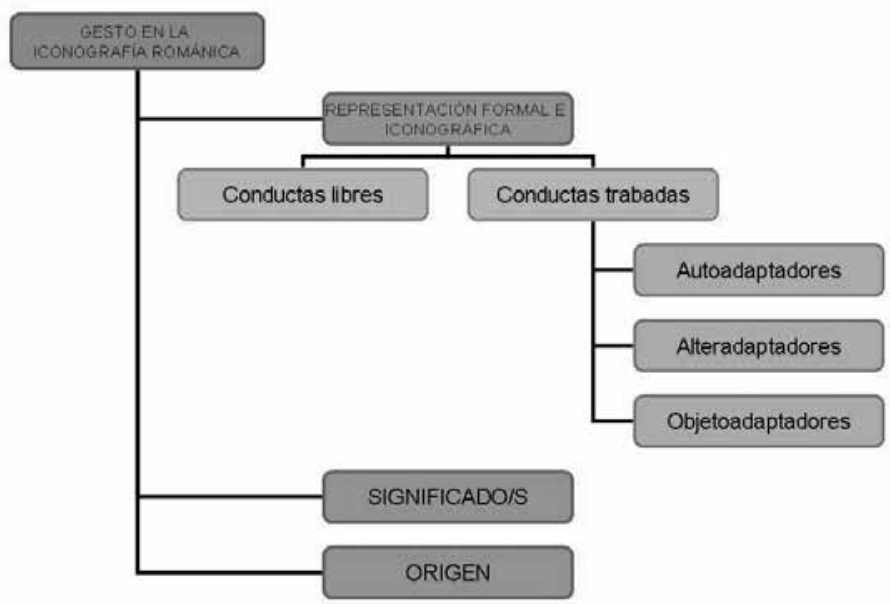

Fig. 1. Esquema del procedimiento metodológico.

En este sentido, realizamos una primera clasificación de los gestos según su forma. Así, llevamos a cabo una distinción entre los gestos, posturas y maneras libres, es decir, manifestaciones gestuales que implican a un único elemento del cuerpo humano, y aquellos que son trabados, que implican el contacto o interacción de dos o más elementos corporales ${ }^{12}$. Estos últimos los hemos dividido, a su vez, en autoadaptadores, que aluden el contacto de dos partes de un mismo cuerpo, alteradaptadores, en los que intervienen al menos dos personas, y objetoadaptadores, que remiten a una interacción con los objetos.

Los diferentes gestos analizados se organizan, además, siguiendo un criterio vertical ${ }^{13}$. Se ha dividido el cuerpo en tres niveles: superior, en relación con la cabe-

12 Entendemos por libre "cualquier acto cinético o posición realizado por una o más partes del cuerpo o extremidades en el espacio, es decir, por sí mismas, sin tocar otras partes del cuerpo ni ayudarse de ningún recurso objetual", mientras que con el término trabado nos referimos a "cualquier movimiento o posición en que las manos se tocan mutuamente o hacen contacto con otras partes del cuerpo, o en que cualquier parte del cuerpo hace contacto con otro cuerpo o, sobre todo, con objetos". Cf. POYATOS, Fernando, La comunicación no verbal, Madrid, Istmo, vol. I, pp. 185-224.

13 J. E. Finol sugiere que el cuerpo humano puede dividirse siguiendo tres criterios diferentes. El primero de ellos sería el vertical, según el cual en el cuerpo podemos distinguir los niveles superior, intermedio e inferior; en segundo lugar estaría el horizontal, de acuerdo con el cual el cuerpo quedaría segmentado en lado izquierdo, 
za; intermedio, referido al tronco y extremidades superiores; e inferior, relacionado con las extremidades inferiores. A partir de esta clasificación formal, llevamos a cabo una identificación de los temas iconográficos, tanto de carácter sacro como profano, en los que estos gestos fueron utilizados.

En segundo lugar, tras el análisis de carácter formal e iconográfico, cada una de las variedades gestuales es analizada en función del significado o significados que pudieron adquirir en época románica, así como un intento de aproximación a su origen. A este respecto, es necesario señalar que, en muchas ocasiones, los gestos surgieron en el mundo antiguo y fueron heredados por el mundo medieval. Por ello, se hace necesario un estudio profundo de formas artísticas de las culturas y civilizaciones que poblaron la cuenca mediterránea en épocas anteriores a la Edad Media. Para ello nos apoyamos en fuentes tanto artísticas como literarias, documentales, patrísticas y filosóficas que nos ayudan a esclarecer los diversos significados y el origen que pudieron tener los gestos que encontramos en la iconografía románica.

\section{Ejemplos del procedimiento metodológico}

Como muestras del procedimiento metodológico hemos seleccionado dos ejemplos: la Dextera Dei y el gesto de mesarse los cabellos.

El primero de ellos está relacionado, como decimos, con la representación de la Dextera Dei en la iconografía románica (fig. 2). Un análisis formal e iconográfico de este motivo nos permite advertir que la mano divina aparece en la iconografía románica en dos contextos diferentes: inserta en una escena o un tema iconográfico, o bien aislada, sin relación con otras figuras o motivos.

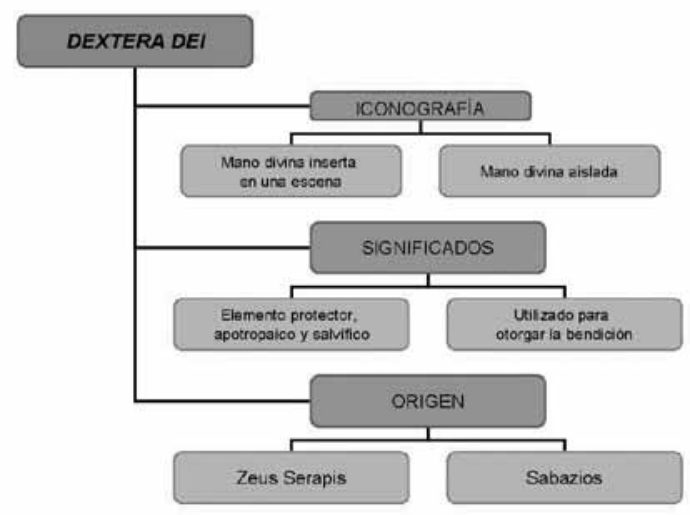

Fig. 2. Ejemplo del procedimiento metodológico. Dextera Dei.

centro y lado derecho; por último, existiría un tercer criterio, que dividiría el cuerpo en frontal y posterior. Véase: FINOL, José Enrique, "Cuerpo y rito: la estructura del gesto en ceremonias públicas", en Los gestos. Sentidos y prácticas, DeSignis, no 3, 2002, pp. 81-90. En nuestro caso, hemos optado por seguir el criterio vertical. 
Los significados más relevantes que pudo tener este elemento están relacionados con su carácter apotropaico, protector y salvífico, así como el de bendición. El poder y la fuerza divinos se manifiestan a través de la mano, ya que es la parte del hombre a la que se le presupone mayor actividad, con la que se ejercitan y consiguen mayor número de acciones. Además, la mano puede acompañar, facilitar y enfatizar la palabra humana ${ }^{14}$.

En tercer lugar, nos planteamos hipótesis sobre el origen de la representación de una mano aislada que hace alusión a la divinidad. De esta manera, incluso en época prehistórica, el hombre ha plasmado gráficamente esa parte del cuerpo que considera más viva y activa. Las civilizaciones más antiguas representaron y creyeron en el poder sobrenatural de la mano. Todas ellas concibieron a las divinidades como seres antropomorfos que, por tanto, poseían brazos y manos; con ellos ayudaban, castigaban y protegían a los fieles en la tierra. Mientras las culturales más orientales representaron a sus dioses con múltiples manos y bra$\operatorname{zos}^{15}$, en la cuenca mediterránea un único brazo hizo alusión al conjunto de la divinidad.

Quizá el elemento más próximo a la concepción de la Dextera Dei del mundo medieval lo encontramos en relación con el culto a varios dioses de época helenística, entre los que se encuentran Zeus Serapis y Sabazios. En relación con ellos, se conservan una gran cantidad de manos de bronce, diseminadas por varios países de la cuenca mediterránea y que tienen un carácter votivo. En relación seguramente con el arte helenístico, la iconografía hebrea tomó este motivo para plasmar gráficamente la personalidad divina. Coetáneamente, el primer arte cristiano, quizás a través del arte judío, adoptó esta mano, así como la mayoría de sus significados; principalmente los de protección y bendición ${ }^{16}$. Desde entonces se convertiría en el principal símbolo divino del cristianismo.

El segundo de los ejemplos que hemos seleccionado está relacionado con la presencia, en la iconografía románica, de personajes que colocan sus manos a ambos lados del cuero cabelludo (fig. 3). Se trata de la plasmación plástica del gesto de mesarse los cabellos que, al ser trasladado al campo artístico, se convierte en una postura de carácter, por tanto, estático. A diferencia del caso descrito anteriormente, nos encontramos ante una conducta trabada de carácter autoadaptador, es decir, las manos se encuentran en una posición en la que hacen contacto con otra parte del cuerpo humano.

${ }^{14}$ GROSCHER, G. (ed.), Beredte Hände. Die Bedeutung von Gesten in der Kunst des 16. Jahrhunderts bis zur Gegenwart, (hrsg. von G. Groschner), Salzburg, Residenzgalerie, 2004; KIRIGIN, Martin, La mano divina nell'iconografia cristiana, Città del Vaticano, Pontificio Instituto di Archeologia Cristiana, 1976; LECLERCQ, Dom H., voz "Main", en Dictionaire d'archéologie chrétienne et de liturgie, Paris, Letouzey et Ané, 1934, t. X, cols. 1206-1207.

15 Es el caso, por ejemplo, del dios Shiva en la India.

16 GRABAR, André, Las vías de la creación en la iconografia cristiana, Madrid, Alianza Forma, 2003, p. 47. 


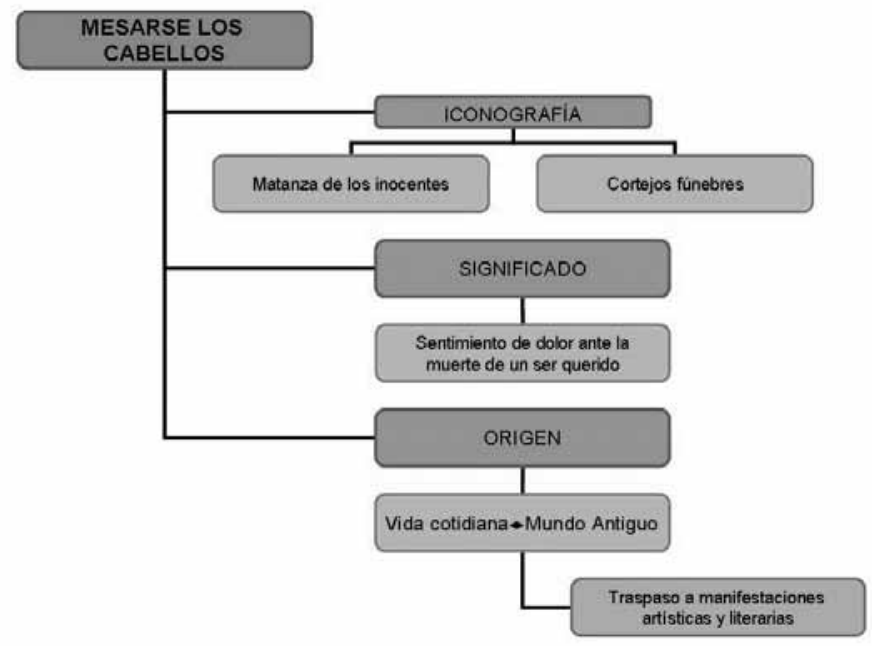

Fig. 3. Ejemplo del procedimiento metodológico. Gesto de mesarse los cabellos.

Un rastreo de escenas en los que este gesto adquiere protagonismo nos ha permitido detectar que son dos los temas iconográficos fundamentales del Románico hispano en los que podemos detectar esta actitud. El primero de ellos procede de un pasaje bíblico neotestamentario, la matanza de los Inocentes ${ }^{17}$. Los personajes que realizan el gesto de mesarse los cabellos son las madres de los niños asesinados por los sicarios del soberano hebreo. Así sucede en los capiteles de Santa Cecilia y Santa María la Real de Aguilar de Campoo ${ }^{18}$; en el capitel interior de la iglesia de San Juan de Duero; y en la representación de esta escena en las arquivoltas de las portadas de Moradillo de Sedano y Santo Domingo de Soria. El segundo de los contextos donde hallamos la presencia frecuente de personajes con las manos situadas a ambos lados de la cabeza es en la representación del cortejo fúnebre en escenas de carácter funerario, sobre todo en las esculpidas en los sepulcros. Muestras elocuentes son el sepulcro de Blanca de Navarra conservado en el panteón real del monasterio de Santa María la Real de Nájera, varios sepulcros relacionados con el taller de las Huelgas y el sepulcro portugués de Egas Moniz. Además, la presencia de esta conducta en las escenas de cortejos fúnebres en los sepulcros románicos constituye el punto de partida para lo que será su posterior desarrollo en época gótica, donde lo hallamos por doquier ya que se convierte en una de las actitudes

\footnotetext{
17 Este pasaje es narrado en Mateo, 2, 16, así como en algunos evangelios apócrifos, entre los que se encuentran el Protoevangelio de Santiago, XXII,1 y el Evangelio del Pseudo Mateo, XVII, 1.

${ }_{18}$ El capitel de la matanza de los Inocentes de la iglesia de Santa Cecilia se encuentra in situ, mientras que el capitel doble de Santa María actualmente se conserva en Madrid, en el Museo Arqueológico Nacional. Cfr. BRAVO JUEGA, María Isabel, MATESANZ, Pedro, Los capiteles del monasterio de Santa María la Real de Aguilar de Campoo (Palencia) en el Museo Arqueológico Nacional, Salamanca, Caja de Ahorros y Monte de Piedad de Salamanca, 1986, pp. 74-80.
} 
indispensables en este tipo de imágenes. Es el caso, por ejemplo, del sepulcro del obispo Rodrigo Álvarez, en la catedral de León, o las tablas pintadas del sepulcro de Sancho Saiz de Carrillo, procedentes de Mahamud de Esgueva y hoy en el Museo Nacional de Arte de Cataluña.

En cuanto al significado de esta postura, podemos decir que es siempre el mismo, independientemente del contexto iconográfico en el que lo encontremos. Expresa el sentimiento de dolor ante la muerte de un ser querido. En este sentido, es necesario tener en cuenta que, en la vida real, se trata de una conducta de carácter violento, es decir, es un gesto de autoagresión o autolesión, que produce un fuerte dolor físico. Se utiliza un dolor físico suplementario para exteriorizar un dolor interno, mora ${ }^{19}$. Por ello, al ser codificado y pasado al ámbito de la representación iconográfica, generalmente lo encontramos en escenas con las que se pretende transmitir situaciones límite, de alto valor expresivo.

Por último, en lo que se refiere a su origen, se trata de una actitud que es reflejo de la vida cotidiana. Fue un comportamiento presente en la mayor parte de las culturas y civilizaciones antiguas de la cuenca mediterránea, en las que era utilizado en ceremonias funerarias y cortejos fúnebres, junto con otros como arañarse la cara, rasgarse las vestiduras, golpearse el pecho o levantar los brazos. Es decir, existía un ritual de duelo, una liturgia funeraria que, paralelamente a su desarrollo en la vida real, fue traspasado al campo artístico, así como a la literatura, principalmente a la poesía ${ }^{20}$.

En el mundo antiguo encontramos continuas referencias a este gesto, tanto en la creación literaria como artística ${ }^{21}$. Sin embargo, con la llegada del cristianismo y, durante parte de la época altomedieval, la presencia de este gesto prácticamente desaparece en todas las manifestaciones. La razón puede deberse a la condena establecida por la Iglesia en cuanto a la realización de posturas, gestos y actitudes exageradas. Rechazó toda muestra exagerada de dolor ante la muerte basándose en la doctrina de la fe y confianza en la salvación del cristiano tras su fallecimiento ${ }^{22}$. Sin embargo, hacia el siglo IX, este tipo de conductas reapareció con fuerza en dis-

19 Véase QUENTEL-TOUCHE, Cecile, voz "Douleur", en Dictionnaire critique d'iconographie occidentale, Rennes, Presses Universitaires de Rennes, 2003, p. 275.

20 De hecho, algunos autores, como E. Gombrich, consideran que la conducta ritualizada más típica que influyó en el lenguaje y las convenciones del arte es el ritual del duelo por lo muertos, existente en todas las sociedades primitivas. Cfr. GOMBRICH, Ernst, "Gesto ritualizado y expresión en el arte", en La imagen y el ojo. Nuevos estudios sobre la psicología de la representación pictórica, Madrid, Debate, 2000, pp. 74-75.

${ }^{21}$ Ya en el siglo VIII a. C., Homero describe el uso de este gesto en gran número de situaciones, tanto en La Odisea como en La Ilíada. En esta última, por ejemplo, Aquiles se mesa los cabellos como muestra de dolor ante la muerte de Patroclo: HOMERO, La Ilíada, ed. y trad. A. López Eire, Madrid, 1999, Cátedra, XVIII, 22, p. 346. Igualmente realistas son dos figuras cretenses de plañideras que se tiran violentamente de los cabellos; proceden de Kidonia, han sido fechadas en el siglo IV a. C. y hoy se conservan en el Museo Arqueológico de Hania. Hemos señalado más ejemplos, tanto de fuentes literarias como plásticas, en: MIGUÉLEZ CAVERO, Alicia (2010), op. cit., pp. 246 y ss.

22 Así lo demuestra san Pablo, por ejemplo, en la I Epístola a los Tesalonicenses, 4, 13-18. 
tintos ámbitos y se fueron haciendo cada vez más frecuentes en el campo artístico $\mathrm{y}$ en las fuentes literarias, tanto en ambientes orientales como occidentales ${ }^{23}$.

\section{Resultados y conclusiones del estudio}

La acotación cronológico-temporal de la investigación, el material de trabajo empleado, el planteamiento metodológico y el procedimiento seguido a la hora de realizar el corpus gestual nos han permitido extraer unas conclusiones sobre la gestualidad y su importancia en la iconografía románica de los reinos hispanos.

La primera de las consideraciones que importa señalar es la existencia de un lenguaje gestual plástico de enorme riqueza en la iconografía románica en general $\mathrm{y}$, en la de los reinos hispanos, en particular.

En segundo lugar, en lo que respecta al análisis formal e iconográfico que hemos llevado a cabo, podemos concluir que ese lenguaje gestual tan rico lo hallamos en el ámbito de la creación de imágenes tanto sacras como profanas. Los mismos gestos, actitudes, posturas y conductas fueron utilizados por los artistas para plasmar, por ejemplo, escenas religiosas y juglarescas.

Por lo que se refiere a las particularidades gestuales que hemos encontrado en la iconografía románica peninsular hispana respecto al grueso del románico europeo, el principal aspecto a señalar es que, de manera general, el lenguaje gestual presente en la plástica de los reinos hispánicos responde a los parámetros de la estética románica de otras regiones. Los gestos utilizados por artistas de otros territorios europeos los hallamos, de igual manera, en las manifestaciones plásticas de los reinos hispanos.

En tercer lugar, en cuanto al significado de los gestos que hallamos en la iconografía románica, todas las conductas representadas en el arte románico tienen un carácter primario: todos los gestos son incluidos en la imagen medieval con un propósito definido, para emitir un mensaje determinado. No hallamos, por tanto, gestos secundarios ni acciones mecánicas o espontáneas. En cuanto al propio significado de las posturas, existen, fundamentalmente, dos tipos de actitudes: por un lado, aquellas conductas que conllevan un solo significado. Son susceptibles de ser utilizadas en diversos contextos, situaciones, escenas y temas iconográficos y, además, ser adoptadas por diversos personajes. Sin embargo, mantienen siempre una misma carga semántica. Por otro lado, son frecuentes también las posturas que

${ }^{23}$ M. Barasch señala que se trata de una fórmula de dolor muy frecuente en el arte y la literatura del mundo antiguo, pero que pareció desaparecer en el arte de los siglos VII y VIII y reapareció asociada con el renacimiento carolingio. Para este investigador, este tipo de gestos específicos, herederos claros de la cultura, los ritos y el arte antiguos, es un claro exponente de la persistencia o el renacimiento de la cultura antigua en el lenguaje medieval de los gestos y, al mismo tiempo, de las transformaciones que sufren con el paso del tiempo. Cfr. BARASCH, Moshe (1976), op. cit., pp. 18, 20 y 34-35. 
acogen varios sentidos y pueden ser adoptadas, asimismo, por distintos personajes. Es decir, una conducta gestual puede significar varios conceptos, que pueden ser similares o bien diametralmente opuestos ${ }^{24}$.

En cuarto y último lugar, por lo que respecta al origen de los gestos, es posible señalar diversos tipos. Existen, por ejemplo, conductas universales. Éstas no tienen origen en un lugar específico sino que han surgido en contextos espaciales y momentos históricos diferentes, aunque mantienen siempre el mismo significado. Sin embargo, el grueso más significativo de las actitudes que encontramos en la iconografía románica nació, desde el punto de vista plástico, en culturas o civilizaciones anteriores y fue asimilado por el arte medieval. Finalmente, podemos señalar también la presencia de gestos "regionales", es decir, posturas que surgieron ex novo en la plástica románica y no fueron heredadas de manifestaciones artísticas ni anteriores ni coetáneas. Éste es el grupo más pequeño de actitudes que podemos hallar en la plástica románica de los reinos hispanos.

24 Esta categoría sería muy similar a la que, en el campo de la antropología, Desmond Morris denomina los gestos multimensajes. Cf. MORRIS, Desmond, Manwatching. A Field Guide to Human Behavior, New York, H. N. Abrams, 1977, pp. 41-42. En estos casos, a fin de descifrar el sentido concreto que el gesto tiene en una imagen o escena determinada, bien sea como espectadores o como investigadores, debemos tener en cuenta los demás componentes que conforman la imagen, así como el propio contexto en el que ésta fue elaborada. Éstos serán los que nos ofrezcan la posibilidad de decantarnos por uno u otro de los significados posibles. 